\title{
Undergraduate research
}

\author{
Winning the battle for students' hearts and minds
}

$\mathrm{B}$ iomedical and basic biological research are now probably better funded than physics and chemistry. Moreover, biological research has proven that it can have a direct impact on public health and economic development, with the result that the prospects for the life sciences are apparently better than ever. But this success creates its own problem: the demand for talented researchers is quickly outpacing supply. This trend has worried many policy makers, scientists, educators and politicians, and has encouraged them to find new ways to attract young students into research.

\section{...for research, you need an individual experience, and that's enormously time and resource expensive}

As disciplines, biology and medicine are actually faring better than chemistry and physics, which have suffered from a spate of university department closures in recent years. Even so, there is a continuing failure to attract sufficient numbers of gifted students to all scientific disciplines. The USA was the first to recognize that this problem begins at the undergraduate level, and to identify a solution to actively recruit students to the sciences and retain them at the graduate level. The US analysis proposed that students were losing interest in their subjects because of a lack of engagement with genuine research, and that they would be more likely to continue to postgraduate level and beyond if they were engaged in real, frontline research, rather than just conventional coursework (Russell et al, 2006). Both the US federal government and many individual universities created several schemes, which resulted in the US National Science Foundation (NSF; Arlington, VA) revising its grant conditions in order to encourage undergraduate research in 2001.

Most European countries have come to similar conclusions about the importance of undergraduate research, but have yet to incorporate this into funding and policy decisions. "In the USA, the NSF almost expects that large grant applications will include within them undergraduate placements, and it is part of their grant proposal assessment criteria," commented Alan Jenkins, a fellow of the Reinvention Centre for Undergraduate Research at Oxford Brookes University in the UK. "Here in the UK, if anyone were to put a similar thing into a Research Council grant application it would get struck out. There is a significant difference in cultures."

But the culture in the UK is changing at the university level. This is most evident at the Cambridge-MIT Institute (Cambridge, UK), which was established specifically to develop new approaches to education, entrepreneurship and research. It is a joint project by Cambridge University and the Massachusetts Institute of Technology (MIT; Boston, USA), and MIT has extended its Undergraduate Research Opportunities programme-which started as early as 1969to Cambridge University students to provide funding for exchange visits between the two institutions. According to Jenkins, this represents the sort of cultural shift that is needed in the UK. The aim should be to adopt the best practices from the USA in order to offer students better opportunities to do real research. The objective of the programme is to bring teaching and research closer together, since they often coexist uneasily. Many university researchers regard teaching as a necessary impediment to their research, which is required to earn their salaries, rather than as an integral part of their work.
I $\mathrm{n}$ fact, it is the growing gap between teaching and research that needs to be overcome. Many US universities are richly endowed in terms of finances and facilities, but they often offer close research involvement only to the best or most promising students. Most European universities follow more egalitarian principles, especially in the UK, where the drive towards undergraduate research is coincident with a rapid proliferation in student numbers. The UK Government's current target of bringing $50 \%$ of $18-30$ year olds into higher education by 2010 might be soon achieved, although numbers are currently stuck at $43 \%$. However, this is still a significant achievement when compared with just 10\% a generation ago (Anon, 2003).

\section{It is one thing for a student to participate in a major research project with close supervision, but quite another to be cited in the literature}

But quantity is not synonymous with quality in education, and having more students makes it harder to give each one a real experience of original research. Celia Knight, director of the undergraduate school in the Faculty of Biological Sciences at Leeds University, UK, conceded, "The big challenge we face is simply the number of students in higher education [...] We can have bigger lecture theatres, and e-learning can help with the numbers, but for research, you need an individual experience, and that's enormously time and resource expensive."

These limitations create a risk that students are treated as cheap labour, rather than getting first-hand experience of actual 
research. John Creighton, director of the Centre for Excellence in Teaching and Learning (CETL) in Applied Undergraduate Research Skills at Reading University, UK, said, "Engaging undergraduates in research could be seen as cheap labour if it is not crafted well, but the better way of viewing this - and what is driving this in the USAis thinking about the sustainability of the country's research base. In a competitive world, the UK and Europe need to ensure that we capture the minds of people who are potentially interested in continuing on to do R\&D, either within higher educational establishments or within industry."

Two things are therefore required to engage undergraduates in research work. First, both teachers and scientists have to change their attitudes towards involving students in research, and second, universities need more resources in the form of facilities and staff availability. This has been appreciated in the UK, which has already created various CETLs-modelled on US practices - to boost undergraduate research with a total investment of $£ 315$ million (€470 million) over the five academic years from 2005/06 to 2009/10. Each CETL has been given a capital sum ranging from $£ 800,000$ to $£ 2$ million, plus recurrent funding each year of between $£ 200,000$ and $£ 500,000$ depending on the number of students.

S uch schemes rely on the assumption that students will be enthused by active research during their degree courses. Although this seems obvious-rather like the idea that children will progress faster in smaller class sizes-hard evidence to support it has been lacking, until recently. Of course there has been plenty of anecdotal evidence from the USA, where the first undergraduate research programmes began 40 years ago, but it is only during the past few years that statistical data became available to support this assumption. Most recently, a study conducted between 2003 and 2005 by the NSF found that undergraduate students who partook in active research, rather than standard practical coursework, were more likely to continue with graduate courses and pursue subsequent careers in science (Russell et al, $2006,2007)$. The study involved 15,000 students across all disciplines in science and technology. The findings were overwhelmingly positive, but equally welcome was the conclusion that for a minority of studentsabout one in six-involvement in research helped them to decide that a science career was not right for them.

Generally, the more research students did, the more interested they became in science. The survey revealed that the likelihood of a student staying with science to PhD level and beyond increased continually with the amount of time that they spent on research. Of those students with no research involvement at all, only $8 \%$ went on to

A Ithough the USA and the UK are now tackling the issue, Germany has so far made the most progress in producing well-trained graduates, according to Elisa Izaurralde, Director and Scientific Member of the Max Planck Institute for Developmental Biology in Tübingen, Germany. "Most universities in Germany offer very good undergraduate training," she said. "In fact, I have participated in international PhD programmes and the best students were always from Germany."

Izaurralde attributed this success to the fact that German students study for between 4 and 6 years, concluding with a diploma that involves up to one year of working on a research project. Yet she attributed the high quality of graduates and entrants to PhD programmes largely to the emphasis that German universities place on practical work and early research experience. This includes publication and presentation of results to others and moving to different laboratories, sometimes internationally. "The students have the opportunity to see different labs with different resources, and they will be better prepared to choose a good lab for their PhD," Izaurralde said. Jörg Braun, one of Izaurralde's students, is conducting his research project as part of a team studying the translational regulation of proteins, and spends as much time in the laboratory as in the lecture undertake

a PhD. The corresponding figures were $13 \%$ for students spending 1-3 months on research during their undergraduate courses, $15 \%$ for those doing 4-6 months, $20 \%$ for $7-12$ months and $30 \%$ for more than 12 months. Even allowing for the fact that those doing more research might well be brighter students at the best universities, these are compelling figures.

The authors of the study concluded that their results vindicate the efforts of the NSF to increase undergraduate participation in research. However, in the USA, most resources are still focused on selected students. Even at major research universities, such as Stanford (Palo Alto, CA, USA), only about $25 \%$ of undergraduates gain authentic research experience. Much of this research is conducted in summer schools, for which vigorous selection criteria are often applied. 
"Last year I discovered my strong interest [in] the RNA field. After getting familiar with [the] details and literature I knew that I wanted to learn more about it," Sauer said.

Although Braun's and Sauer's work involve genuine cutting-edge research, it is not always possible to give students such a high-quality experience. Knight thinks that, in many cases, students will not be involved long enough to play a more active part. It is one thing for a student to participate in a major research project with close supervision, but quite another to be cited in the literature. This raises the question of whether undergraduates really can conduct important research suitable for publication in peerreviewed journals. Knight is rather doubtful: "In the past it's been difficult for students to get into peer reviewed journals, because the quality and quantity of the work has not been deemed high enough," he commented.

Myles Boylan, Program Officer in the Directorate for Education and Human Resources at the NSF, is equally sanguine. "I know of no examples of ground-breaking undergraduate research," he said. "Except in exceptional cases, undergrads are simply not at a stage of development where serious contributions should be expected." One reason that limits the scope of undergraduate research is the fact that research-in X-ray crystallography, for example-can require the use of highly sophisticated methods, experience and access to expensive equipment. Interesting results are thus more likely to come from areas where enthusiasm or sudden insights are needed, rather than technical expertise or experience.

Yet undergraduate research can be quite sophisticated. A team of seven undergraduate students at Johns Hopkins University (Baltimore, MD, USA) developed an oral strip for delivering a vaccine against rotavirus, which causes diarrhoea and vomiting in young children. The main problem with the current live vaccine is that it must be refrigerated to ensure its delivery in an active form, which limits its use in poor and remote regions. The students developed a system whereby the vaccine is enclosed in a thin film and is taken just by sucking it like a sweet. It has a coating that prevents its breakdown by stomach acid before reaching the gut and will also, with further refinement, enable the live vaccine to survive at tropical temperatures.

An increasing amount of research in biology and medicine is done in silico, outside the traditional laboratory. This trend could provide students with better opportunities for getting involved in research, as computing resources can be made available more readily than 'wet lab' facilities. Indeed the development of internet-based computing infrastructures will help to provide students at less well-endowed universities with genuine research opportunities. Boylan said of in silico research, "[w] ithout it, most statesupported institutions of higher education and even many private institutions would not be able to provide many of their students with authentic research experiences." He added that it would also present the possibility of giving students live data from experiments to conduct their own investigations, even if they were not part of the research team itself.

$\mathrm{f}$ the aim is to give students a taste of life in a laboratory-in silico or otherwisefinancial incentives or remunerations might also help. Many keen students will not need to be 'bribed' to enter a laboratory, but if research is an optional extra involving work during holidays, then a little incentive might be helpful. This, at least, is the opinion of the Max Planck Institute in Germany, which pay students by the hour for their time in the laboratory. In France there is also a growing trend towards paid compulsory training in research laboratories-according to Denis Poinsot, Maître de Conferences at the Université de Rennes-but without the allocation of additional resources. However, despite this generosity, student salaries are usually very low and often less than half the minimum wage.

Alternative incentives to encourage students to participate in laboratory research are academic credits, with rewards for successfully completed or well-performed projects. Furthermore, it might also help to offer to publish a student's research in dedicated journals, given that prestige can be just as motivating as money. This is why Poinsot has created the journal, Biologos, in which students at Rennes University can publish their work, after scrutiny by a professional panel. It also gives students their first experience of preparing manuscripts within the peer-review process.

But the incentives need to go both ways. Greater involvement of research in teaching will require more time to be given to teaching by research staff and will divert some resources away from research. This naturally means that extra money is needed, in addition to flexible approaches for sharing both human expertise and access to equipment. This is easier to accomplish when setting up new undergraduate programmes at a regional or national level, rather than ad hoc schemes within individual universities. Boylan commented: "Many of the undergraduate research projects that are created from scratch do share equipment and faculty resources with students from many different institutions [...] Many of these sites are essentially real laboratories. For example, many chemistry labs have sophisticated NMRs [nuclear magnetic resonance machines], and many bio labs have confocal microscopes."

\section{Without better opportunities for students to be involved in real research, the battle for their hearts and minds will be lost}

Despite these difficulties, there is a continuing commitment at the university level to invest more in undergraduate research. Without better opportunities for students to be involved in real research, the battle for their hearts and minds will be lost. Some educators and scientists would therefore like to extend these types of opportunities to high schools to attract more young people to science in the first place. Boylan, for example, thinks there is a strong case for this: "The key design considerations are cost and devising appropriate experiences. We have discovered that involving high-school students in summer science camps is a great way to recruit them to undergraduate majors in science, when these camps are carefully designed." In addition to the costs, however, there is some debate as to whether teachers are really able to provide meaningful research experiences. But if the aim is to entice more young people into research and retain them, then it seems appropriate that research involvement should extend to high schools and nurture scientific ability and interest from an early age.

\section{REFERENCES}

Anon (2003) White Paper-The Future of Higher Education. London, UK: Department for Education and Skills

Russell SH, Hancock MP, McCullough J (2006) Evaluation of NSF Support for Undergraduate Research Opportunities. Arlington, VA, USA: National Science Foundation

Russell SH, Hancock MP, McCullough J (2007) THE PIPELINE: benefits of undergraduate research experiences. Science 316: 548-549

\section{Philip Hunter}

doi:10.1038/sj.embor.7401039 